\title{
Multi-Dependent Criteria Supplier Selection with Uncertain Performance Evaluation
}

Author(s): O. Anuchitchanchai, K. Suthiwartnarueput, P. Pornchaiwiseskul

Source: Journal of International Logistics and Trade 2018; 16(2):32-45

Published by: Jungseok Research Institute of International Logistics and Trade, Inha University

DOI: https://doi.org/10.24006/jilt.2018.16.2.032

The Journal of International Logistics and Trade is an official journal published by Jungseok Research Institute of International Logistics and Trade, Inha University, Korea. JILT welcomes manuscripts that advance the practice and science of logistics, trade, and other related fields.

Frequency: Quarterly (March, June, September, December)

Stable URL: https://www.ejilt.org

The Jungseok Research Institute of International Logistics and Trade is a specialized academic research institute representing Inha University and the Inha Foundation in Korea. The institute aims to become a representative institute in Northeast Asia in the research of logistics and trade.

Stable URL: https://jrieng.inha.ac.kr

(C) Copyright. Jungseok Research Institute of International Logistics and Trade.

This is an Open-Access article distributed under the terms of the Creative Commons Attribution NonCommercial License (http://creativecommons.org/licenses/by-nc/4.0/) which permits unrestricted noncommercial use, distribution, and reproduction in any medium, provided the original work is properly cited 


\title{
Journal of
}

\section{International Logistics and Trade}

\section{Multi-Dependent Criteria Supplier Selection with Uncertain Performance Evaluation}

\author{
O. Anuchitchanchai*, K. Suthiwartnarueput, P. Pornchaiwiseskul \\ Logistics and Supply Chain Management Program, Chulalongkorn University, Bangkok, Thailand
}

\begin{abstract}
ARTICLE INFO
Article history:

Accepted 1 May 2019

Keywords:

Supplier selection

Skewness

Supplier performance

evaluation
\end{abstract}

Received 16 December 2017

\begin{abstract}
Nowadays businesses tend to compete with rivals by improving capability to meet customer demands. One of the key to improve logistics efficiency of a firm is to select appropriate supplier. In the past, to select the most suitable supplier, most people evaluated performance by using average performance or variance from historical data but did not mentioned skewness. In other words, skewness impact on supplier performance is ignored by researchers and buyers. In fact, supplier with greatest average performance does not confirm to be the most suitable one because of uncertainties which make its performance skew either to the left or right, i.e., lower or higher than expectation. Therefore, this empirical study aims to discover and determine the important role of skewness on supplier selection problem. After identifying influential criteria on supplier selection, we analyze skewness effect on suppliers' performance in each criterion by surveying real data of suppliers' performances. Skewness effect can be rated in 3 levels; no effect, moderately effect, and highly effect. The results show that, there is only one criterion with no skewness effect, which is price. Criteria which have high skewed performance, for both of medium-sized and large-sized buyers, are lead time, product quality and reliability, and on-time delivery. Also, skewness has higher effect on suppliers' performance of medium-sized buyers than large-sized buyers. The conclusion surprisingly shows that, skewness is the best index to distinguish between good and bad suppliers, while mean is the worst index.
\end{abstract}

\section{Introduction}

Nowadays businesses tend to compete with rivals by improving capability to meet customer demands. In terms of logistics and supply chain management, there are several activities which a firm should conduct, for example, customer service and support, purchasing and procurement, transportation, inventory management, etc. Among these activities, purchasing and procurement is an activity that manufacturing companies have been facing and focusing due to its significance in company overall effectiveness (Bevilacqua and Petroni, 2002; Ellram and Carr, 1994). In purchasing and procurement activity, there are six decisions to make orderly (Aissaoui et al., 2007) as shown in Figure 1.

From these decision processes, one of the key to improve logistics efficiency of a firm is to select appropriate supplier. To compete with rivals, suppliers play important role on buying firm. Purchasing cost sometimes contribute more than $50 \%$ of total cost of goods sold (Humphreys et al., 2007). Therefore, it is obviously that supplier performance has effect on firm performance. In other words, supplier selection and evaluation are able to reduce cost and enhance quality (Aksoy and Öztürk, 2011).

Many researchers have been dealing with supplier selection problem for decades. But those researches ignored consideration of higher degree of uncertainties which is skewness. For example, Chai et al. (2013) reviewed supplier selection approaches. Some approaches included uncertainty in several categories, such as, imprecise data, gray values,

\footnotetext{
* Corresponding author: Logistics and Supply Chain Management Program, Chulalongkorn University, Phayathai Road. Pathumwan Bangkok 10330, Thailand; Email: ornicha@mut.ac.th
} 
uncertain demand. But the authors did not mention any paper, which considering performance skewness. Another example is the study from Luzzini et al. in 2014. The authors did a research to survey vender evaluating by interviewing companies from several industries, including electronics industry. Most of them evaluate by scoring each potential supplier based on their set of criteria but ignoring skewness value. Generally, when selecting supplier, buying firm should select the one which have highest expected performance (i.e., mean) and low risk (i.e., variance). But considering only mean and variance may not sufficient as mentioned earlier because literally supplier's performance could be fluctuated for a period of time. That is to say, supplier whose performance has no skewness does not point out that it is good supplier. This research aims to study the effect of skewness on supplier performance.

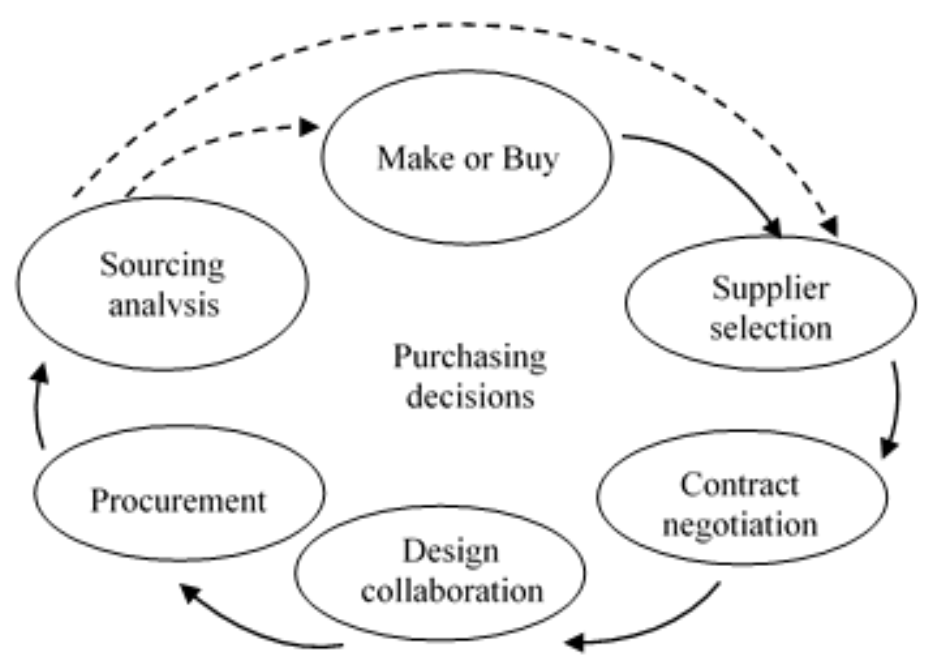

Figure 1. Decision processes in purchasing and procurement activity (Aissaoui et al., 2007)

For example, let us raise the example of deliverability, which is measured by $\%$ on-time delivery. Supposed that each graph in Figure 2 represents on-time delivery performance of different suppliers (A-D). To compare between A and B, both of them have same average $\%$ on-time delivery, as mean of these two suppliers are equal. But the variance of $\mathrm{A}$ is greater than B as we can see that graph A is more spread out than B. In this case we can say that supplier B is better than A even though their average performances are equal since B's performance is more stable or has lower variance. In other words, lower variance or SD means lower risk. But to compare between C and D, both suppliers have equal mean and SD. If buyer only takes mean and variance into account, then buyer may conclude that both of them have equal performance. But if buyer also takes skewness into consideration, despite the fact that $\mathrm{C}$ and $\mathrm{D}$ has equal average, both may perform different performance. Figure C shows that its performance skews to the right (positive-skew) while (D) skews to the left (negative-skew). This means that most likely $\mathrm{C}$ has lower \% on-time delivery than expected while $\mathrm{D}$ has higher since D's mode exceeds means and vice versa for C. Assuredly, buyers prefer left-skewed \% on-time delivery to either right-skewed or symmetrical $\%$ on-time delivery distribution.

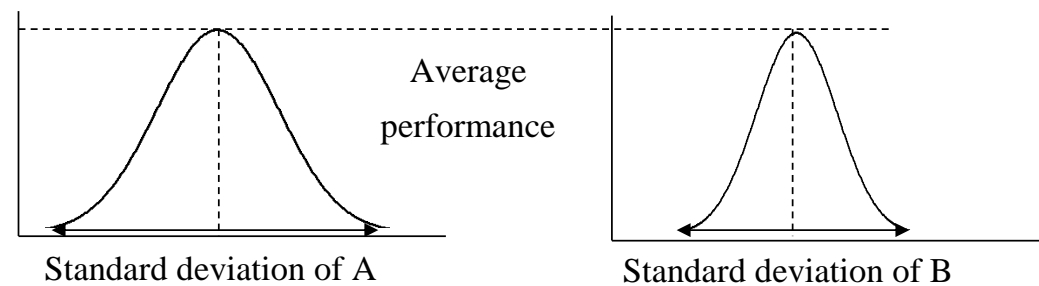

(A)

(B)

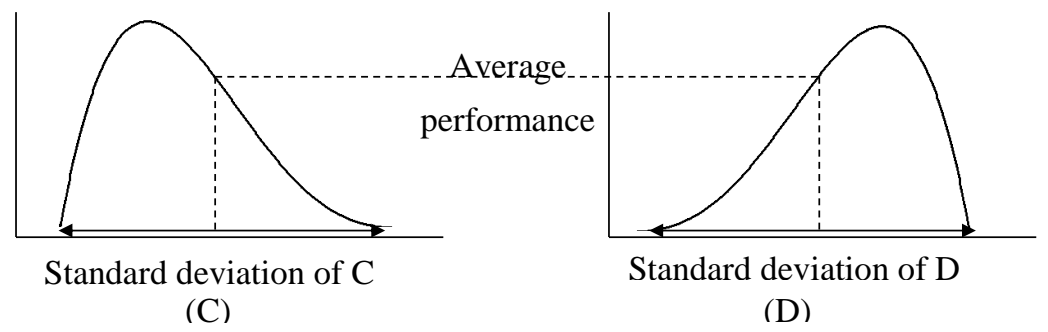

Figure 2. Example of on-time delivery performance of possible supplier A-D

Please be noted that there are 2 types of performance. One is performance with preference of negative skewness or 
the higher of performance index means better efficiency, such as \% on-time delivery. In this case buyers would prefer left-skewed performance. Conversely, another one is performance with preference of positive skewness or the lower of performance index means better efficiency, such as cost and lead time. In this case buyers would prefer right-skewed rather than left-skewed performance.

In Thailand, electronics industry is one of the most important industries. With skillful labor, geographic advantage and transport facilities, Thailand has been being the largest electrical appliances manufacturing base in ASEAN. However, due to ASEAN Economic Community (AEC) that has been established by the beginning of the year 2016, despite of gaining new opportunities, the competition among this region becomes higher. Regional manufacturers have to adjust themselves for a situation like this. One of the key issues is improving their performance. Not surprisingly, supplier selection has positive relationship to buying firm's performance (Kannan and Tan, 2002; Nelson et al., 2005). Improving supplier selection could affect to manufacturer's performance as well. There are many researches developing supplier selection method in Asian region. For example, case study in Hong Kong by Choy et al. (2002), case study in China by Chiou et al. (2008) and Yan (2009), in Taiwan by Lee et al. (2009) and Chen and Chao (2012), and the study in Malaysia by Bhattacharya et al. (2010). Nevertheless, there appears to be no case study of developing method for supplier selection decision in Thailand. This research attempts to provide the idea to develop more effective and practical way of selecting and evaluating supplier by introducing the importance of skewness.

The main contribution of this research is providing the evidence of skewness effect existence on supplier performance. The benefit of this research has two-folds. One is for buying firms, another one is for suppliers. Once buying firms realize the importance of skewness, they can improve their efficiency by selecting more appropriate suppliers by including skewness in evaluating process. For suppliers, this research provides the guidance to suppliers of which performance perspective should be emphasized and improved in order to become first priority supplier.

This research is organized into 6 sections, Section 2 is literature review of ANP approach and importance of skewness. Section 3 describes methodology. Section 4 presents result analysis. Section 5 is the discussion and implication from this research. Section 6 addresses the conclusion and future research.

\section{Literature review}

\subsection{Analytic network process}

It is no doubt that supplier selection is multi-criteria decision-making problem (MCDM). Many MCDM techniques have been used to tackle with this decision problem. One of the most widely used approach for MCDM problem is Analytical hierarchy process or AHP (Jharkharia and Shankar, 2007). AHP is the method introduced by Saaty in 1980. The basic concept of AHP is to obtain important weight of each criteria, then calculate score of each alternative based on all criteria and rank the alternatives. The core of AHP approach is hierarchical decision model structuring. Starting with the objective (i.e. goal) as the first or top level, based on multiple criteria in lower level which can separate into subcriteria if needed, and alternatives at the bottom level. The comparison of importance among criteria and preference among alternatives uses pairwise comparison. To make pairwise comparisons, the decision maker is required to give preference number to compare between two items. Normally, the scale of preference (i.e. intensity of importance) is rated from 1 to 9. This approach is able to deal with both of quantitative and qualitative criteria and simplify complex problem into hierarchical form. For example, Ghodsypour and O'Brien (1998) applied AHP technique to determine important weight of criteria as well as overall score of alternate suppliers. Li and Zhao (2009) used AHP to select the most suitable for automotive industry. Similar to Chen and Wu's study in 2013, but this research applied AHP technique to select supplier for semiconductor manufacturer. The steps of AHP can be summarized into five steps as follows: 1) construct the network structure after identifying goal of problem at the top level, affecting factor or criteria must be determined. then construct the network structure; 2) make pairwise comparisons of criteria; 3) check the consistency of pairwise judgment and re-do step 2 if needed; 4) convert result from pairwise comparisons into important weights; and 5) calculate total score of each alternative and rank the alternatives.

Although AHP is well-known and widely used among researchers but it seems to have a shortcoming that it cannot well reflect real case (Aragonés-Beltrán et al., 2010). In AHP we assume that criteria are independent. That is to say, no effect of one criterion on other criterion. But in real case, supplier selection criteria have effect on each other (Eshtehardian et al., 2013) which means criteria are always having interrelation. For example, in supplier selection problem with cost and quality criteria. Obviously, buying firms prefer low cost and high quality but with lower cost, buying firm may accept lower quality if its quality still be acceptable. This implies that it may have interaction between clusters as well as interaction between elements from different level. Thus, it is impossible to construct decision model in hierarchical structure. To overcome this shortcoming, decision model is construct and represented by network instead of hierarchical structure. This decision model is called Analytic Network Process (Saaty, 1999). We could say that it is AHP with considering the assumption of criteria dependence between cluster and elements. Consequently, some researchers try to overcome this shortcoming by applying ANP approach, for example, the study of Gencer and Gürpinar (2007) and Xiao et al. (2012). 


\subsection{Importance of skewness}

In financial and economic research, there is a problem of portfolio selection which the investor must select the optimal portfolio. In process of selection, not only expected return should be considered because the portfolio with greatest expected return does not mean the most suitable one. That is to say, the portfolio with the best expected return is not necessarily having minimum variance (Markowitz, 1952). Therefore, variance has been used widely for risk measure (Huang, 2012). To evaluate or measure portfolio performance, there are many researches on portfolio performance evaluation based on mean-variance-skewness framework. At the beginning, the researchers evaluate portfolio based on mean and variance and ignored skewness. The mean-variance model is introduced by Markowitz in1952. Mean-variance model is extensively applied by many researchers, for example, Fletcher (1994), Chiu and Wong (2011), Castellano and Cerqueti (2014). Despite of a vast study used mean-variance theory, afterward, researchers found that the third moment should not be ignored then skewness was included to evaluate performance. Joro and $\mathrm{Na}$ (2006) developed portfolio performance measurement based on mean-variance-skewness framework and compared the efficiency obtained from both of mean-variance model and mean-variance-skewness. The results prove that the efficiency obtained from combining those three moments is better than traditional evaluation. In other words, efficiency obtained from mean-varianceskewness is better than evaluating efficiency based on merely mean and variance. But in logistics research, there is no research thoroughly studies on skewness importance and effect. None ever applied this concept on supplier selection problem. This research fills these gaps and bring the skewness into consideration.

The objective of supplier selection problem is similar to portfolio selection. In portfolio selection, the investors should select portfolios which have optimum return, while in supplier selection problem, buying firm choose supplier who have best performance. Therefore, the skewness should not be overlooked in order to evaluate supplier performance before making a choice. Supposed that there are n possible suppliers for buyer to select denoted by $X_{1}, X_{2}, \ldots, X_{\mathrm{n}}$. Let $E_{i}$ is the average performance that the buyer could get from each possible supplier and $V_{i}$ is the variance of each. Figure 3 shows all set of $(E, V)$ from all possible choices of supplier. Each point represents average performance (mean) and risk (variance) of each supplier. The border of the surface is called efficient surface or efficient frontier. The buyer should select suppliers which fall on the border as they are denoted as efficient combinations. Additionally, based on mean-variance theory, buyer should select suppliers which give maximum average performance $(E)$ for given variance $(V)$ or less or those with minimum variance for given average performance $(E)$ or more.

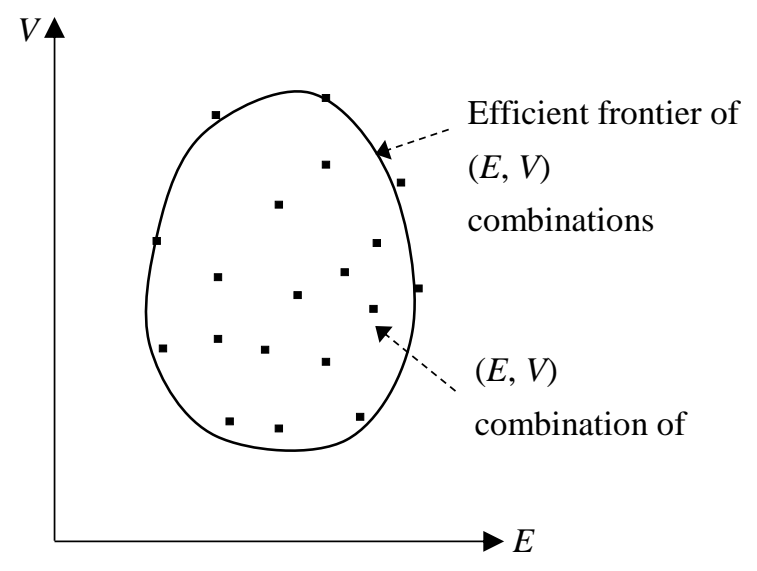

Figure 3. Combination of mean-variance of possible choice (modified from Markowitz (1952))

From explanation above, it is clearly that decision making in supplier selection is trade-off between average performance (mean) and risk (variance) for all possible suppliers which fall on efficient frontier. The question is, whether skewness has effect and plays important role on supplier performance.

Therefore, we separate supplier performance into three characteristics, namely, 3D performance perspective (3DPP) as follows:

- Performance efficiency: This performance type means the average efficiency of supplier measured by mean.

- Performance stability: With good stability, variance or standard deviation of supplier's performance should be low. Therefore, this performance type is measured by variance or standard deviation.

- Performance tendency: As aforementioned, it does not mean that supplier with no difference between most-likely performance (mode) and average performance is favorable. Because performance of suppliers could skew either to the left or right. Hence, this performance reflects the asymmetrical direction of efficiency which measured by skewness. 
Table 1. Summary of supplier selection criteria in previous studies

\begin{tabular}{|c|c|c|c|c|c|c|c|c|c|c|c|c|c|c|c|c|c|c|c|c|c|c|c|c|c|c|c|}
\hline \multirow[b]{2}{*}{ Authors } & \multicolumn{23}{|c|}{ Dickson's criteria } & \multicolumn{4}{|c|}{ Additional criteria } \\
\hline & $\overrightarrow{0}$ & 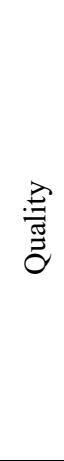 & $\begin{array}{l}\frac{\lambda}{0} \\
\frac{D}{0} \\
0\end{array}$ & 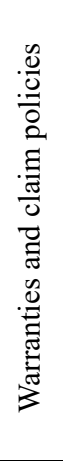 & 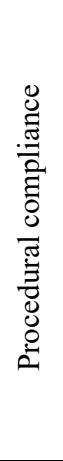 & 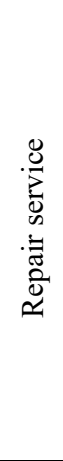 & 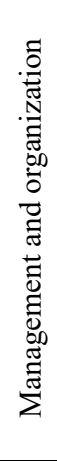 & 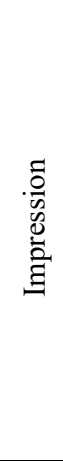 & 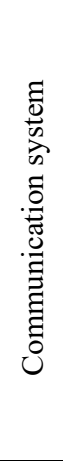 & 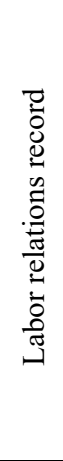 & 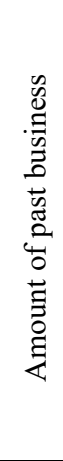 & 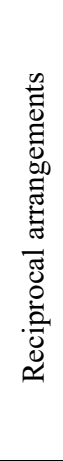 & 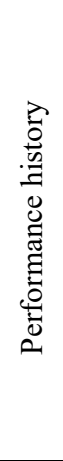 & 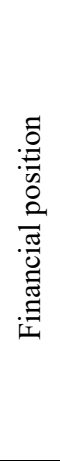 & 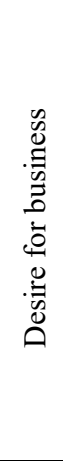 & 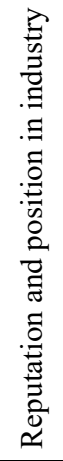 & 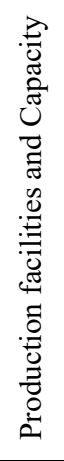 & 兽 & 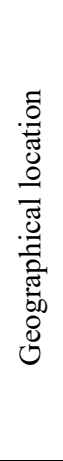 & 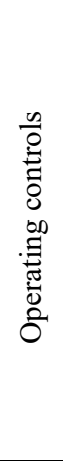 & 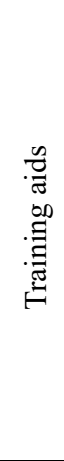 & 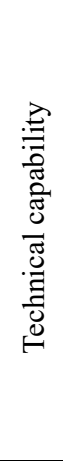 & 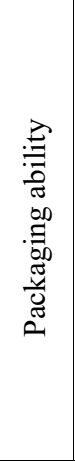 & 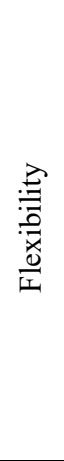 & 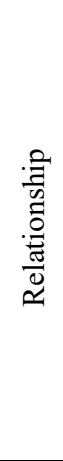 & 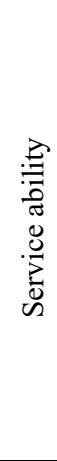 & 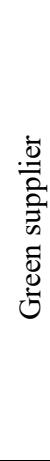 \\
\hline Dickson $(1966)^{*}$ & 1 & 1 & 1 & 1 & & & & & & & & & 1 & & & & 1 & & & & & & & & & & \\
\hline Weber et al. (1991)* & 1 & 1 & 1 & & & & & & & & & & & & & & 1 & & 1 & & & 1 & & & & & \\
\hline Weber (1996) & 1 & 1 & 1 & & & & & & & & & & & & & & & & & & & & & & & & \\
\hline Weber \& Desai (1996) & 1 & 1 & 1 & & & & & & & & & & & & & & & & & & & & & & & & \\
\hline Albino \& Garavelli (1998) & 1 & 1 & 1 & & & & 1 & & & & & & & & & & & & & & & 1 & & & & & \\
\hline De Boer et al. (1998) & 1 & 1 & & & & & & & & & & & & 1 & & & & & 1 & & & & & & & & \\
\hline Verma \& Pullman (1998) & 1 & 1 & 1 & & & & & & & & & & & & & & & & & & & & & 1 & & & \\
\hline Ghodsypour \& O'Brien (1998) & 1 & 1 & 1 & & & & & & & & & & & & & & 1 & & & & & & & & & & \\
\hline Jian et al. (2000) & 1 & 1 & 1 & & & & & & & & & & & & & & 1 & & 1 & & & & & & & & \\
\hline Ghodsypour \& O'Brien (2001) & 1 & 1 & 1 & & & & & & & & & & & & & & 1 & & & & & & & & & & \\
\hline Cakravastia et al. (2002) & 1 & & 1 & & & & & & & & & & & & & & & & & & & & & & & & \\
\hline Choy et al. (2002) & 1 & 1 & 1 & & & & & & & & & & & 1 & & & & & & & & & & & & 1 & \\
\hline Katsikeas et al. (2004) & 1 & 1 & 1 & 1 & 1 & & & & & & & & & & & & & & & & & 1 & & & & & \\
\hline Gencer \& Gürpinar (2007) & & 1 & 1 & & & & 1 & & 1 & & & & & 1 & & & 1 & & 1 & 1 & 1 & 1 & 1 & & & 1 & \\
\hline Chiou et al. (2008) & 1 & 1 & 1 & & & & & & & & & & & & & & & & & & & & & & & 1 & 1 \\
\hline Lee et al. (2009) & 1 & 1 & 1 & & & & 1 & & & & & & & 1 & & & & 1 & & & & 1 & & 1 & & & 1 \\
\hline Li \& Zhao (2009) & & 1 & & & & & 1 & & 1 & & & & & & & 1 & & & 1 & & & 1 & & & 1 & 1 & 1 \\
\hline Yan (2009) & 1 & 1 & 1 & & & & & & 1 & & & & & & & & 1 & & & & & & & & & 1 & 1 \\
\hline Bhattacharya et al. (2010) & & 1 & 1 & & 1 & & 1 & & & & & & & 1 & & 1 & & 1 & & & & 1 & & 1 & & & \\
\hline Aksoy \& Öztürk (2011) & 1 & 1 & 1 & & & & & & & & & & & & & & & & 1 & & & & & & & & \\
\hline Mafakheri et al. (2011) & 1 & 1 & 1 & & & & & & & & & & & & & & & & & & & & & & & & 1 \\
\hline Chen \& Chao (2012) & 1 & 1 & 1 & & & & 1 & & & & & & & 1 & & & 1 & & & & & 1 & & 1 & 1 & & \\
\hline Xiao et al. (2012) & & 1 & 1 & & & & & & 1 & & & & 1 & 1 & & & 1 & & & & 1 & 1 & & & 1 & & \\
\hline Chen \& Wu (2013) & 1 & 1 & 1 & 1 & 1 & & & & & & & & & & & & 1 & & & & & 1 & & 1 & & & \\
\hline Dargi et al. (2014) & 1 & 1 & 1 & & & & & & & & & & & & & 1 & 1 & & 1 & & & 1 & & & & 1 & \\
\hline
\end{tabular}




\section{Research methodology}

\subsection{Identification of criteria}

One of the important questions on supplier selection problem is what are the critical criteria affecting to the decision and how to measure the importance level of each criterion. Back to 1966, Dickson introduced 23 critical factors which affecting vendor selection. Notwithstanding this study was published since 1966, some of criteria are still valid and considered as influential factors on supplier selection by many researchers. Apparently, supplier selection is multi-criteria decision making. Also, not only quantitative criteria should be considered but also qualitative criteria (Ghodsypour and O'Brien, 1998). Selecting a suitable supplier is trading off among those influential factors. Table 1 shows influential criteria on supplier selection problem used in previous researches. It should be noted that some criteria are renamed to match with Dickson's criteria depending on its definition.

From Table 1, most widely used criteria including criteria which are suitable and extensively considered in Thai electronics industry are selected and confirmed by experts, i.e., purchasing managers from several companies. There are six main criteria with thirteen sub-criteria in this research. The following parts explain the definition of each criteria.

- Cost: This is classified into 2 sub-criteria, namely, Price and Other cost.

- Delivery: It has 2 sub-criteria, i.e., Lead time and On-time delivery.

- Quality: First sub-criterion is quality of product to meet buying firm's specification measured by return rate, which is named as Product quality and reliability. Another one is Continuous improvement ability which means the effort and ability of supplier to increase performance for the future.

- Supplier condition and relationship: This includes 3 sub-criteria. Capacity and flexibility means ability to produce order from buyer with responsiveness to changing or additional requirement from buyer. Technical capability is technological proficiency of supplier, not only the current one but also the potential of future technological research and development (R\&D) on both of product design and production process. The last one is the cooperation from supplier to improve buyer's capability and efficiency in terms of product development and process development which is named as Collaborative development.

- Green supplier: This comprises of 2 sub-criteria which are Green manufacturing process and Green product and design.

- Supplier risk: In this research, supplier risk is divided into 2 sub-criteria depends on cause of lower expected performance which are Natural risk and Human risk.

\subsection{Determining target group}

Although this research has set manufacturers in electronics industry as target group. But there is a large number of manufacturers in this industry. Also, characteristics of manufacturers in this industry are very heterogeneous due to many types of products and manufacturers. A method that could be used to classified manufacturing types is using Thailand Standard Industrial Classification (TSIC). TSIC is a 5-digit-code generated by Department of Industrial Works, Ministry of Industry, Thailand. Based on TSIC, manufacturing companies in electronics industry can be grouped into 7 types as shown in Table 2.

Table 2. Clustering of Thailand's electronics industry

\begin{tabular}{|c|c|c|c|}
\hline \multirow{2}{*}{ Types of manufacturer } & \multicolumn{3}{|c|}{ Size of company } \\
\hline & Small & Medium & Large \\
\hline Electronic devices, part and coil & 152 & 28 & 7 \\
\hline Computer storage equipment & 25 & 4 & 2 \\
\hline Lighting equipment & 50 & 24 & 9 \\
\hline Transformer, uninterrupted power supply, battery, electric wire & 270 & 138 & 48 \\
\hline Computer part, print circuit board, electronic mainboard & 22 & 16 & 34 \\
\hline Home electrical machine & & & \\
\hline Stereo, television & 502 & 177 & 162 \\
\hline Refrigerator, fan, washing machine, air-conditioner & 493 & 173 & 78 \\
\hline Other home electrical machines & 23 & 1 & 1 \\
\hline VDO recorder, camera, lens & 11 & 12 & 12 \\
\hline Total & 1548 & 573 & 353 \\
\hline
\end{tabular}

In this research, home electrical machine which is the nearest tier to end customer has been selected as target group. Because suppliers of this manufacturing type are companies who produce, for example, electronics device, motor, coil, electric wire, which are still in electronics industry. But if electronics devices are selected as target group, suppliers of this manufacturing type fall on other industry, such as, plastic industry, steel industry, rubber industry. Home electrical machine is selected in order to avoid such circumstance. Also, only medium and large-sized manufacture are selected as 
target group. Because of the possibility to have no standard and no system in small manufacturers, the result may have much variance if small-sized manufacturers are including. Hence, total population size is 592 companies.

\subsection{Questionnaire design}

After the set of criteria were formulated, we designed the questionnaire asking about criteria weight and performance evaluation. Questionnaire is separated into 2 main sections. First section is used for criteria weighting, another section is used for performance evaluating.

\section{Questionnaire 1}

For the first section, questionnaire is designed to ask the respondents to compare given pairs of criteria. Questions are divided into 5 parts based on the level of preference structure, such as, level of relative importance among all main criteria by assuming criteria are independent, level of relative importance among main criteria by assuming interrelation, etc. The example of question in this section is shown below:

Question: Based on the goal of supplier selection, which main criteria is more important and how many times of the relative importance?

\begin{tabular}{|c|c|c|c|c|c|c|c|c|c|c|c|c|c|c|c|c|c|c|}
\hline Cost & 9 & 8 & 7 & 6 & 5 & 4 & 3 & 2 & 1 & 2 & 3 & 4 & 5 & 6 & 7 & 8 & 9 & Quality \\
\hline Cost & 9 & 8 & 7 & 6 & 5 & 4 & 3 & 2 & 1 & 2 & 3 & 4 & 5 & 6 & 7 & 8 & 9 & Delivery \\
\hline Cost & 9 & 8 & 7 & 6 & 5 & 4 & 3 & 2 & 1 & 2 & 3 & 4 & 5 & 6 & 7 & 8 & 9 & Supplier condition and relationship \\
\hline Cost & 9 & 8 & 7 & 6 & 5 & 4 & 3 & 2 & 1 & 2 & 3 & 4 & 5 & 6 & 7 & 8 & 9 & Green supplier \\
\hline Cost & 9 & 8 & 7 & 6 & 5 & 4 & 3 & 2 & 1 & 2 & 3 & 4 & 5 & 6 & 7 & 8 & 9 & Supplier risk \\
\hline
\end{tabular}

\section{Questionnaire 2}

The second section of questionnaire is designed to ask the respondents to evaluate historical performance of potential suppliers for each criterion. In questionnaire, respondent will be asked to evaluate between two current suppliers who providing same material or part. One is supplier who has first priority to be selected. In other words, this represents good supplier. Another one is supplier who would be the last choice to be selected which express bad supplier. Respondent will be asked to rate performance of each supplier based on each criterion. Performance will be measured in three characteristics; 1) performance efficiency measured by mean, 2) performance stability measured by standard deviation, and 3) performance tendency measured by skewness.

Asking respondent to evaluate suppliers' standard deviation and skewness is not easy. In order to obtain these two characteristics, the respondent will be asked to evaluate lower and upper bound of performance, i.e. minimum and maximum level of criterion performance, and most often occurred performance, i.e. mode which provided by each supplier. The standard deviation will be calculated using the estimation of range, i.e. the difference between maximum and minimum level of performance obtained from questionnaire. This estimation is proved and proposed by Hozo et al. (2005) and it is showed in equation (1). The skewness will be calculated using pearson's coefficient of skewness which is estimating skewness by mean and mode obtained from questionnaire as shown in equation (2)

$$
\begin{aligned}
& S D=\frac{\text { Range }}{6} \\
& S k=\frac{\bar{X}-\text { Mode }}{S D}
\end{aligned}
$$

where $S D$ is standard deviation; Range is difference between lowest and highest of the range; $S k$ is skewness; and Mode is most often

\begin{tabular}{|c|c|c|c|c|}
\hline & Average price & $\begin{array}{l}\text { Minimum } \\
\text { price }\end{array}$ & $\begin{array}{l}\text { Maximum } \\
\text { Price }\end{array}$ & Price fluctuation \\
\hline Price & & & & $\begin{array}{l}\text { Based on historical data, most-often-occur-price of raw material } \\
\text { from first priority supplier compared to average price is: } \\
\text { not different } \\
\begin{array}{l}\text { lower, most likely equals to } \\
\text { higher most likely equals to }\end{array}\end{array}$ \\
\hline
\end{tabular}
occurred performance. The example of performance evaluation of sub-criteria of price is shown below:

\subsection{Survey conducting}


After set of criteria were formulated, then the survey is conducted by both of face-to-face interview and questionnaire. The respondents in this research are purchasing managers and procurement managers of medium and large-sized home electrical machine manufacturers. The respondents are required at least 10 years of experience. The ratio of face-to-face interview to questionnaire is about $69 \%$ to $31 \%$. For questionnaire, 30 questionnaires were distributed and 24 questionnaires were received, with $80 \%$ response rate. For face-to-face interview, 53 companies were interviewed. Totally, the sample sized in this research is 77 companies.

Purchasing and procurement experts from each company was interviewed or requested to fill out the questionnaire. As explained in previous section, the data obtained from questionnaire section 1 will be used to analyze important weight of each criteria based on ANP approach. Another data is performance data of two types of supplier as mentioned earlier. This data will be used to analyze whether it has different performance perspective between these two suppliers, especially skewness.

\section{Result analysis}

\subsection{Importance of criteria}

Before discussing about skewness effect, the importance of each criterion should be discussed first. In surveying the respondents were requested to compare all criteria based on ANP approach to obtain the important weight of each criterion. After receiving pairwise comparison, consistency ratio (CR) is calculated. If there is inconsistency, which CR is greater than acceptable level (0.1), then respondent is asked to re-judge the pairwise. Then the criteria important weight of each questionnaire is calculated. From totally 77 respondents, the overall weights of each criterion are shown in Table 3.

Table 3. Overall relative importance of criteria for supplier selection by ANP analysis

\begin{tabular}{|c|c|c|c|c|}
\hline Main criteria & Sub-criteria & Overall weight & Overall rank & Dimension rank \\
\hline \multirow{2}{*}{ Cost } & Price & 0.0869 & 2 & \multirow{2}{*}{ 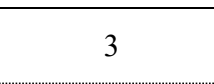 } \\
\hline & Other cost & 0.0751 & 8 & \\
\hline \multirow{2}{*}{ Delivery } & Lead time & 0.0910 & 1 & \multirow{2}{*}{2} \\
\hline & On-time delivery & 0.0750 & 9 & \\
\hline \multirow{2}{*}{ Quality } & Product quality and reliability & 0.0786 & 5 & \multirow{2}{*}{4} \\
\hline & Continuous improvement ability & 0.0806 & 3 & \\
\hline \multirow{3}{*}{$\begin{array}{l}\text { Supplier condition and } \\
\text { relationship }\end{array}$} & Capacity and flexibility & 0.0791 & 4 & \multirow{3}{*}{1} \\
\hline & Technical capability & 0.0766 & 6 & \\
\hline & Collaborative development & 0.0678 & 13 & \\
\hline \multirow{2}{*}{ Green supplier } & Green manufacturing & 0.0711 & 11 & \multirow{2}{*}{6} \\
\hline & Green product and design & 0.0690 & 12 & \\
\hline \multirow{2}{*}{ Supplier risk } & Natural risk & 0.0755 & 7 & \multirow{2}{*}{5} \\
\hline & Human risk & 0.0736 & 10 & \\
\hline
\end{tabular}

\subsection{Importance of criteria}

The research hypothesis is if skewness of supplier performance affects to buyer decision. As mentioned earlier, performance in this research can be classified into 2 types. The first is performance, which the expected greater value than average is preferred. In other words, it is negative skewness preference. Another one is performance, which the expected lower value than average is preferred, i.e. positive skewness preference. According to set of criteria in this research, each type of skewness preference is shown as followings:

Type I: Positive skewness preference: Price, Other cost, Lead time, Product quality and reliability

Type II: Negative skewness preference: On-time delivery, Continuous improvement ability, Capacity and flexibility, Technical capability, Collaborative development, Green manufacturing, Green product and design, Natural risk, Human risk

After the survey was done, the data of performance obtained from questionnaire are transformed into 3 perspectives, which are, mean, standard deviation and skewness using equation (1) and (2). The results are analyzed and summarized as shown in Table 4 and Table 5, categorized by size of company. To minimize the variation, distinguishing among type of manufacturers was also done. But in practically, a company produces not only products which fall on its TSIC type as mentioned earlier but other products which are in different TSIC. Also, some companies changed their product types but did not change their TSIC number. Therefore, it is unable to classify based on type of manufacturers using TSIC of Department of Industrial Works, Ministry of industry, Thailand, as mentioned earlier. Hence, only size classification is analyzed in this research which are classified into medium $(\mathrm{M})$ and large (L) company. 
Although we indicated that, in this research, performance perspective is defined into 3 characteristics, efficiency measured by mean, stability measured by standard deviation and tendency measured by skewness, only 2 indexes, which are CV and skewness, are shown in Table 4 and 5, respectively. Table 4 presents the ratio of standard deviation to the mean, i.e. coefficient of variation (CV). Hence this statistical measure combines the perspective of mean and standard deviation into one. The lower of CV means the better supplier. For skewness index, Bulmer (1979) set the rule of skewness interpretation as following ranges:

$$
\begin{array}{ll}
S k \leq-1 \text { or } S k \geq-1 & : \text { Highly skew } \\
-1<S k \leq-1 / 2 \text { or } 1 / 2 \leq S k<1 & : \text { Moderately skew } \\
-1 / 2 \leq S k<1 & : \text { Approximately symmetrical }
\end{array}
$$

\begin{tabular}{|c|c|c|c|c|c|c|c|}
\hline \multirow{3}{*}{$\begin{array}{l}\text { Main } \\
\text { criteria }\end{array}$} & \multirow{3}{*}{ Sub-criteria } & \multicolumn{6}{|c|}{ Supplier category } \\
\hline & & \multicolumn{3}{|c|}{ Good } & \multicolumn{3}{|c|}{$\mathrm{Bad}$} \\
\hline & & Overall & $\mathrm{M}$ & $\mathrm{L}$ & Overall & $\mathrm{M}$ & $\mathrm{L}$ \\
\hline \multirow{2}{*}{ Cost } & Price & 0.0316 & 0.0320 & 0.0311 & 0.0401 & 0.0415 & 0.0383 \\
\hline & Other cost & 0.0679 & 0.0768 & 0.0549 & 0.0790 & 0.0965 & 0.0479 \\
\hline \multirow[b]{2}{*}{ Delivery } & Lead time & 0.0616 & 0.0622 & 0.0608 & 0.0802 & 0.0851 & 0.0747 \\
\hline & $\begin{array}{l}\text { On-time } \\
\text { delivery }\end{array}$ & 0.0248 & 0.0216 & 0.0284 & 0.0306 & 0.0308 & 0.0304 \\
\hline \multirow{2}{*}{ Quality } & $\begin{array}{l}\text { Product } \\
\text { quality and } \\
\text { reliability }\end{array}$ & 0.2751 & 0.2276 & 0.3171 & 0.2889 & 0.3168 & 0.2564 \\
\hline & $\begin{array}{l}\text { Continuous } \\
\text { improvement } \\
\text { ability }\end{array}$ & 0.0328 & 0.0329 & 0.0327 & 0.0344 & 0.0325 & 0.0367 \\
\hline \multirow{3}{*}{$\begin{array}{l}\text { Supplier } \\
\text { condition } \\
\text { and } \\
\text { relationship }\end{array}$} & $\begin{array}{l}\text { Capacity and } \\
\text { flexibility }\end{array}$ & 0.0339 & 0.0352 & 0.0322 & 0.0436 & 0.0455 & 0.0412 \\
\hline & $\begin{array}{l}\text { Technical } \\
\text { capability }\end{array}$ & 0.0362 & 0.0352 & 0.0372 & 0.0436 & 0.0453 & 0.0415 \\
\hline & $\begin{array}{l}\text { Collaborative } \\
\text { development }\end{array}$ & 0.0376 & 0.0391 & 0.0358 & 0.0546 & 0.0565 & 0.0520 \\
\hline \multirow{2}{*}{$\begin{array}{l}\text { Green } \\
\text { supplier }\end{array}$} & $\begin{array}{l}\text { Green } \\
\text { manufacturing }\end{array}$ & 0.0275 & 0.0294 & 0.0254 & 0.0312 & 0.0315 & 0.0309 \\
\hline & $\begin{array}{l}\text { Green product } \\
\text { and design }\end{array}$ & 0.0335 & 0.0336 & 0.0334 & 0.0285 & 0.0292 & 0.0276 \\
\hline \multirow{2}{*}{$\begin{array}{l}\text { Supplier } \\
\text { risk }\end{array}$} & Natural risk & 0.0412 & 0.0426 & 0.0397 & 0.0685 & 0.0717 & 0.0643 \\
\hline & Human risk & 0.0745 & 0.0760 & 0.0727 & 0.0580 & 0.0617 & 0.0529 \\
\hline
\end{tabular}

\begin{tabular}{|c|c|c|c|c|c|c|c|}
\hline \multirow{3}{*}{ Main criteria } & \multirow{3}{*}{ Sub-criteria } & \multicolumn{6}{|c|}{ Supplier category } \\
\hline & & \multicolumn{3}{|c|}{ Good } & \multicolumn{3}{|c|}{$\mathrm{Bad}$} \\
\hline & & Overall & $\mathrm{M}$ & $\mathrm{L}$ & Overall & $\mathrm{M}$ & $\mathrm{L}$ \\
\hline \multirow{2}{*}{ Cost } & Price & -0.2866 & -0.3767 & -0.1790 & -0.3779 & -0.4357 & -0.3088 \\
\hline & Other cost & 1.1210 & 1.0338 & 1.2251 & -0.6336 & -0.7919 & -0.4446 \\
\hline \multirow{2}{*}{ Delivery } & Lead time & 0.8788 & 0.8033 & 0.9690 & -0.7569 & -0.8645 & -0.6284 \\
\hline & On-time delivery & -0.8436 & -1.0169 & -0.6369 & 0.9133 & 0.8870 & 0.9447 \\
\hline \multirow{2}{*}{ Quality } & $\begin{array}{l}\text { Product quality and } \\
\text { reliability }\end{array}$ & 0.9953 & 1.1871 & 0.7664 & -0.7999 & -0.7074 & -0.9103 \\
\hline & $\begin{array}{l}\text { Continuous improvement } \\
\text { ability }\end{array}$ & -0.4440 & -0.5413 & -0.3279 & 0.8877 & 1.0294 & 0.7186 \\
\hline \multirow{3}{*}{$\begin{array}{l}\text { Supplier condition } \\
\text { and relationship }\end{array}$} & Capacity and flexibility & -0.5426 & -0.5983 & -0.4762 & 1.0451 & 0.9604 & 1.1463 \\
\hline & Technical capability & -0.9720 & -1.0004 & -0.9381 & 0.4059 & 0.4432 & 0.3613 \\
\hline & $\begin{array}{l}\text { Collaborative } \\
\text { development }\end{array}$ & -0.4901 & -0.5606 & -0.4059 & 0.4112 & 0.3052 & 0.5377 \\
\hline \multirow[b]{2}{*}{ Green supplier } & Green manufacturing & -0.3786 & -0.2074 & -0.5829 & 0.3865 & 0.5175 & 0.2303 \\
\hline & Green product and design & -0.3601 & -0.1857 & -0.5682 & 0.4742 & 0.5593 & 0.3726 \\
\hline \multirow{2}{*}{ Supplier risk } & Natural risk & -0.5624 & -0.5235 & -0.6089 & 0.4820 & 0.6439 & 0.2887 \\
\hline & Human risk & -0.8261 & -0.7708 & -0.8922 & 0.5045 & 0.5451 & 0.4560 \\
\hline
\end{tabular}

Table 4. Results of performance evaluation: Coefficient of variation (CV)

Table 5. Results of performance evaluation: Skewness (Sk)

From the results of skewness in Table 5, combines with the rule of skewness from Bulmer, skewness effect is shown in Table 6. When " 0 " represents no effect of skewness (absolute value of skewness is less than 0.5), "+" represents having 
at least moderately effect of positive skewness (skewness value is greater than or equal to 0.5) and "-” represents having at least moderately effect of negative skewness (skewness value is less than or equal to -0.5).

For example, in sub-criteria of green manufacturing, good suppliers of medium-sized buyers have skewness performance equals to -0.2074 . Therefore, no skewness effect exists. In other words, skewness effect in this performance of good suppliers of medium-sized buyers is " 0 " in Table 6 . In the same sub-criteria for large-sized buyers, performance of bad suppliers has skewness value equals to 0.2303. Based on Bulmer's rule, skewness effect of bad suppliers of largesized manufactures in sub-criteria of green manufacturing is " 0 " in Table 6. Another example is sub-criteria of other cost. Good suppliers of medium-sized manufacturers have skewness value equals to 1.0338, therefore, skewness effect is high. Hence, in Table 6, skewness effect is “+”. For bad suppliers, skewness value is equals to -0.7919 , based on Bulmer rule, skewness effect is interpreted as moderate level. Therefore, in sub-criteria of other cost, skewness effect of bad suppliers of medium-sized is "-".

Table 6. Skewness effect based on Bulmer's rule (1979)

\begin{tabular}{|c|c|c|c|c|c|c|c|}
\hline \multirow{3}{*}{ Main criteria } & \multirow{3}{*}{ Sub-criteria } & \multicolumn{6}{|c|}{ Supplier category } \\
\hline & & \multicolumn{3}{|c|}{ Good } & \multicolumn{3}{|c|}{$\mathrm{Bad}$} \\
\hline & & $\begin{array}{l}\text { Expected } \\
\text { direction }\end{array}$ & M & $\mathrm{L}$ & $\begin{array}{l}\text { Expected } \\
\text { direction }\end{array}$ & $\mathrm{M}$ & $\mathrm{L}$ \\
\hline \multirow{2}{*}{ Cost } & Price & + & 0 & 0 & - & 0 & 0 \\
\hline & Other cost & + & + & + & - & - & 0 \\
\hline \multirow{2}{*}{ Delivery } & Lead time & + & + & + & - & - & - \\
\hline & On-time delivery & - & - & - & + & + & + \\
\hline \multirow{2}{*}{ Quality } & Product quality and reliability & + & + & + & - & - & - \\
\hline & Continuous improvement ability & - & - & 0 & + & + & + \\
\hline \multirow{3}{*}{$\begin{array}{l}\text { Supplier condition } \\
\text { and relationship }\end{array}$} & Capacity and flexibility & - & - & 0 & + & + & + \\
\hline & Technical capability & - & - & - & + & 0 & 0 \\
\hline & Collaborative development & - & - & 0 & + & 0 & + \\
\hline \multirow{2}{*}{ Green supplier } & Green manufacturing & - & 0 & - & + & + & 0 \\
\hline & Green product and design & - & 0 & - & + & + & 0 \\
\hline \multirow{2}{*}{ Supplier risk } & Natural risk & - & - & - & + & + & 0 \\
\hline & Human risk & - & - & - & + & + & 0 \\
\hline
\end{tabular}

In Table 6, we can see that there are different results between performance of good suppliers, i.e. key supplier who would be selected with first priority, and bad supplier, i.e. supplier with least favor from buyers. Some performances are not skewed as expected, especially unfavorable suppliers of large-sized manufacturers. This reflects the circumstance when there is no balance between power of buyers and suppliers. large-sized buyers certainly have power over suppliers because of large quantity order. Therefore, they are able to force their suppliers to maintain their efficiency. Even unfavorable suppliers need to maintain their performance, although their performance is not high enough for being first priority suppliers to be selected.

Table 7. Summary of skewness effect

\begin{tabular}{|c|c|c|c|c|}
\hline \multirow{2}{*}{$\begin{array}{l}\text { Rank of } \\
\text { important weight }\end{array}$} & \multirow{2}{*}{ Sub-criteria } & \multicolumn{3}{|c|}{ Skewness effect } \\
\hline & & Overall & $\mathrm{M}$ & $\mathrm{L}$ \\
\hline 1 & Lead time & ++ & ++ & ++ \\
\hline 2 & Price & 0 & 0 & 0 \\
\hline 3 & Continuous improvement ability & + & ++ & + \\
\hline 4 & Capacity and flexibility & ++ & ++ & + \\
\hline 5 & Product quality and reliability & ++ & ++ & ++ \\
\hline 6 & Technical capability & + & + & + \\
\hline 7 & Natural risk & + & ++ & + \\
\hline 8 & Other cost & ++ & ++ & + \\
\hline 9 & On-time delivery & ++ & ++ & ++ \\
\hline 10 & Human risk & ++ & ++ & + \\
\hline 11 & Green manufacturing & 0 & + & + \\
\hline 12 & Green product and design & 0 & + & + \\
\hline 13 & Collaborative development & 0 & + & + \\
\hline
\end{tabular}

To discuss further about the effect of skewness, all criteria performance is classified into groups based on the rule of skewness above. In order to deeply discuss about the real effect of skewness, performance of good and bad suppliers in the same criteria will be considered altogether. If both of them have skewed performance, it is clearly that skewness strongly affects supplier performance. For each criterion, if either good or bad supplier has skewed performance, then it can also say that skewness effect exists. Only if no skewness for both types of suppliers emerges, then there is no effect of skewness at all. The skewness effect of each criterion is summarized and shown in Table 7 . The meaning of each mark 
is defined as below:

$++\quad$ : highly effect: both of good and bad suppliers have at least moderately skewed performance as expected

$+\quad$ : moderately effect: either good or bad suppliers have at least moderately skewed performance as expected

$0 \quad$ : no effect: neither good nor bad suppliers have skewed performance as expected

For example, sub-criteria of lead time for medium-sized manufacturers, since both of good and bad suppliers have skewed performance, skewness effect of this sub-criteria of medium-sized is highly effect (++). Another example is subcriteria of continuous improvement ability. In Table 7, skewness effect of this criteria for large-sized manufacturers is moderately $(+)$, since only bad suppliers have skewed-performance. For sub-criteria of price, since neither good nor bad suppliers have skewed performance, therefore there is no skewness effect on suppliers' performance in this criterion (0), for both of medium and large-sized manufacturers.

The results in Table 7 can be classified into three groups: Group 1. Performance with no effect (0): Most of criteria have fluctuated performance with tendency to differ from average efficiency, only price has no skewness effect on both of good and bad suppliers of M and L-sized companies. This is because of the actual price cannot be much varied as it depends on acceptable price or the contract made by both of buyer and supplier. However, other cost which is in the same main criteria of cost is significantly skewed as shown in the result, so we cannot deny the effect of skewness on cost performance on buyer decision at all.

Group 2. Performance with moderately effect (+): M-sized companies have 4 performances, while L-sized companies have 9 performances in this group. It is no doubt that L-sized manufacturers have sufficient resources more than M-sized. So, they have ability to rapidly adjust themselves to cope with changing in terms of design, process or quantity. Also with their knowledge and technology, they do not rely much on suppliers. Therefore, good supplier in the perspective of Lsized companies are not required to have tendency to improve their performance in the criteria of continuous improvement ability, capacity and flexibility and collaborative development. But this is different from technical capability criteria. Good suppliers of both M and L-sized manufacturers have skewed performance, while having no skewness for bad suppliers. This reflects that technology is important issue for electronics industry, especially in the age that technology is developed so fast. Hence, even unfavorable suppliers need to maintain their performances to meet buyers' expectation. Otherwise they would not survive in this industry. Both of sub-criteria in green supplier, good suppliers of L-sized companies have tendency to have higher performance than expectation since its performance is skewed to the expected direction. While good suppliers of M-sized companies have no tendency since their performance have no skew. Even green issue has become world issue, but for Thai manufacturers, the issue has become mattered for few years, many of them are not still concern much about green criteria as their important weight are ranked in the bottom three. This leads to the thought of unnecessary to pay attention to improve green efficiency, especially for M-sized buyers. However, Lsized companies seem to concern on environmental issues more than M-sized. Therefore, good suppliers of L-sized have skewed performances as shown in the result. In contrast, bad suppliers of M-sized companies have skewed performance while unfavorable suppliers of L-sized companies have no skew. One interesting issue is unfavorable suppliers' performance of other cost criteria for L-sized buyers are no skewed as we expected. Because of buyers' power over suppliers, buyers can force suppliers to monitor their performances in order to avoid failure to meet buyers' expectation even unfavorable suppliers.

Group 3. Performance with highly effect (++): As mentioned earlier, some criteria performance has skewed performance either good or bad suppliers while some are skewed on both of them. In both cases, we can say that skewness effects supplier's performance and buyers' decision and can be used to distinguish between good and bad suppliers. Especially lead time, On-time delivery and product quality and reliability, which their performances of most favorable and most unfavorable suppliers are very different as they are skewed to different directions.

\section{Discussions and implications}

This research studies the effect of skewness and its relationship with supplier performance. The following part is the discussion and implication from the study. Here we will discuss in 2 perspectives as followings:

\subsection{Buyers' managerial implication}

From previous section, it is found that to compare between good and bad suppliers, skewness has strongly impact on their performances. In other words, performance skewness between good suppliers and bad suppliers are different. Therefore, when evaluating supplier performance, buyers should not only compare average performance (mean) or stability of performance (SD or variance), but also bring skewness into consideration, to acquire the proper answer of the best supplier. But bringing skewness into consideration means trade-off among mean, variance, and skewness, which we named as 3D performance perspective (3DPP) as described in section 2. If buyers only focus on performance in short period, only performance efficiency (mean) could be enough. If buyers focus on stable performance, which is possibly to 
have lower performance efficiency but easier to plan or expect the result, only SD could be used. But in Thai electronics industry, the nature of procurement is mostly long-term contract with good relationship and good coordination required from supplier. Hence, it is undeniable that if buyer wants to get the highest efficiency of purchasing and procurement activity, skewness should not be overlooked or omitted when monitoring supplier's performance for a period of time.

\subsection{Suppliers' managerial implication}

For suppliers' contribution, this research provides the guidance to suppliers of which perspective should be improved. By using statistical hypothesis testing to compare the differences of performance between good and bad suppliers, with significance level of 0.05 , the results are shown in Table 8 , ranked by important weight. This table summarizes the effect of each performance perspective in 3DPP on buyer's decision. The tick mark refers to accepting the null hypothesis while the cross mark refers to rejecting the null hypothesis. For example, criteria of lead time, for both of M and L-sized manufacturers, average lead time, standard deviation of lead time, and skewness of lead time, between good suppliers and bad suppliers are different. In other words, all performance perspectives have effects on buyer's decision. Therefore, suppliers should concern on improving their performance in all three perspectives rather than focusing on only average performance. But for continuous improvement ability of M-sized buyers, the result shows that, mean and SD between good and bad suppliers are not different. In other words, mean and SD cannot distinguish between good and bad suppliers. Only skewness effect exists. Therefore, suppliers should focus on improving skewness of performance tendency in order to become good suppliers or first priority supplier to be selected. Therefore, Table 8 provides guidance to suppliers of which perspective should be improved and concerned.

The interesting point obtaining from Table 8 is, for all criteria except price, only a perspective that is different between good and bad suppliers, which matters to buyer's decision, is skewness. So, if suppliers would like to improve themselves and become the favorable supplier, they should focus on their skewness rather than mean or variance. This concludes that skewness should not be neglected when making decision of supplier selecting and evaluating problem.

Table 8. Guidance of which perspective should be improved

\begin{tabular}{|c|c|c|c|c|c|c|c|}
\hline \multirow{3}{*}{$\begin{array}{l}\text { Rank of } \\
\text { important weight }\end{array}$} & \multirow{3}{*}{ Sub-criteria } & \multicolumn{6}{|c|}{ Performance perspective } \\
\hline & & \multicolumn{3}{|c|}{ M-sized buyers } & \multicolumn{3}{|c|}{ L-sized buyers } \\
\hline & & Mean & SD & Sk & Mean & SD & Sk \\
\hline 1 & Lead time & $\checkmark$ & $\checkmark$ & $\checkmark$ & $\checkmark$ & $\checkmark$ & $\checkmark$ \\
\hline 2 & Price & $x$ & $\checkmark$ & $x$ & $\checkmark$ & $\checkmark$ & $x$ \\
\hline 3 & Continuous improvement ability & $x$ & $x$ & $\checkmark$ & $\checkmark$ & $x$ & $\checkmark$ \\
\hline 4 & Capacity and flexibility & $\checkmark$ & $x$ & $\checkmark$ & $\checkmark$ & $x$ & $\checkmark$ \\
\hline 5 & Product quality and reliability & $\checkmark$ & $\checkmark$ & $\checkmark$ & $\checkmark$ & $\checkmark$ & $\checkmark$ \\
\hline 6 & Technical capability & $x$ & $\checkmark$ & $\checkmark$ & $x$ & $\checkmark$ & $\checkmark$ \\
\hline 7 & Natural risk & $\checkmark$ & $\checkmark$ & $\checkmark$ & $\checkmark$ & $\checkmark$ & $\checkmark$ \\
\hline 8 & Other cost & $\checkmark$ & $\checkmark$ & $\checkmark$ & $\checkmark$ & $x$ & $\checkmark$ \\
\hline 9 & On-time delivery & $\checkmark$ & $\checkmark$ & $\checkmark$ & $\checkmark$ & $x$ & $\checkmark$ \\
\hline 10 & Human risk & $\checkmark$ & $\checkmark$ & $\checkmark$ & $x$ & $\checkmark$ & $\checkmark$ \\
\hline 11 & Green manufacturing & $x$ & $x$ & $\checkmark$ & $x$ & $\checkmark$ & $\checkmark$ \\
\hline 12 & Green product and design & $x$ & $x$ & $\checkmark$ & $x$ & $\checkmark$ & $\checkmark$ \\
\hline 13 & Collaborative development & $\checkmark$ & $\checkmark$ & $\checkmark$ & $\checkmark$ & $x$ & $\checkmark$ \\
\hline
\end{tabular}

\section{Conclusions and further study}

Among several activities in logistics and supply chain management, this research focusing on improving efficiency of purchasing and procurement activity. Concentrating on supplier selection problem, this research introduces the important role of skewness and attempt to find the effective and practical way of selecting and evaluating suppliers. In supplier selection problem, normally buying firms choose supplier which has best performance. But supplier with greatest expected performance or highest average performance does not mean the most suitable one. That is to say, actually performance can be measured into 3 perspectives, which are mean, variance, and skewness, as we named as performance efficiency, performance stability and performance tendency, respectively (3D Performance Perspective: 3DPP). Therefore, this research explores skewness effect on supplier performance.

For Thai electronics industry, there are totally 13 criteria affecting buyers' decision. From surveying, this study obtains the result of supplier efficiency in each perspective, both of good supplier, which means supplier who performs well and be the first priority to be selected, and unfavorable supplier, which means supplier who has lowest historical performance and be the last choice to be selected. Upon our hypothesis of skewness effect, either performance skewness of good or bad suppliers can support the existence of skewness effect for all criteria performance except price. One interesting finding is average performance and standard deviation between good and bad suppliers for some criteria are not different, only skewness that matters. It shows the nature of manufacturers in electronics industry that concentrate on tendency to 
improve performance of suppliers than current efficiency. Good suppliers refer to whose performance skew to the right direction. In other words, good suppliers are suppliers who tend to improve themselves continuously.

From the conclusion, the contribution has two-folds, one is for buyers, and another one is for suppliers. For buyers' side, it is undeniable when buyer wants to get the highest efficiency of purchasing and procurement activity, skewness should not be overlooked or omitted, when monitoring suppliers' performance for a period of time. For suppliers' side, this research provides the guidance of which perspective should be improved for each criterion in order to improve themselves and become the most favorable supplier. Therefore, the skewness should not be overlooked in order to evaluate supplier performance before making a choice.

The findings in this study shows that skewness is an index that could be used to represent the tendency of improvement With high skewness, suppliers seem to have higher performance than buyers' expectation and tend to be able to improve their performance. In addition, by improving on skewness, sooner or later, skewed performance seems to gradually shift to the expected direction and be able to transform to normal distribution. Future researchers should study if improving skewness seems to be continuously improved firm's performance like PDCA concept.

\section{References}

Aissaoui, N., Haouari, M., Hassini, E., 2007. Supplier selection and order lot sizing modeling: A review. Computers \& Operations Research 34, 3516-3540.

Aksoy, A., Öztürk, N., 2011. Supplier selection and performance evaluation in just-in-time production environments. Expert Systems with Applications 38, 6351-6359.

Albino, V., Garavelli, A.C., 1998. A neural network application to subcontractor rating in construction firms. International Journal of Project Management 16, 9-14

Aragonés-Beltrán, P., Chaparro-González, F., Pastor-Ferrando, J.P., Rodríguez-Pozo, F., 2010. An ANP-based approach for the selection of photovoltaic solar power plant investment projects. Renewable and Sustainable Energy Reviews 14, $249-264$.

Bevilacqua, M., Petroni, A., 2002. From traditional purchasing to supplier management: A fuzzy logic-based approach to supplier selection. International Journal of Logistics Research and Applications 5, 235-255.

Bhattacharya, A., Geraghty, J., Young, P., 2010. Supplier selection paradigm: An integrated hierarchical QFD methodology under multiple-criteria environment. Applied Soft Computing 10, 1013-1027.

Bulmer, M.G., 1979. Principles of Statistics. Dover, New York.

Cakravastia, A., Toha, I.S., Nakamura, N., 2002. A two-stage model for the design of supply chain networks. International Journal of Production Economics 80, 231-248.

Castellano, R., Cerqueti, R., 2014. Mean-variance portfolio selection in presence of infrequently traded stocks. European Journal of Operational Research 234, 442-449.

Chai, J., Liu, J.N.K., Ngai, E.W.T., 2013. Application of decision-making techniques in supplier selection: A systematic review of literature. Expert Systems with Applications 40, 3872-3885.

Chen, P.S., Wu, M.T., 2013. A modified failure mode and effects analysis method for supplier selection problems in the supply chain risk environment: A case study. Computers \& Industrial Engineering 66, 634-642.

Chen, Y.H., Chao, R.J., 2012. Supplier selection using consistency fuzzy preference relations. Expert Systems with Applications 39, 3233-3240.

Chiou, C.Y., Hsu, C.W., Hwang, W.Y., 2008. Comparative investigation on green supplier selection of the American, Japanese and Taiwanese electronics industry in China. Proceedings of IEEE (Institute of Electrical and Electronics Engineers) International Conference on Industrial Engineering and Engineering Management 2008. Singapore. 1909-1914.

Chiu, M.C., Wong, H.Y., 2011. Mean-variance portfolio selection of cointegrated assets. Journal of Economic Dynamics and Control $35,1369-1385$.

Choy, K.L., Lee, W.B., Lo, V., 2002. An intelligent supplier management tool for benchmarking suppliers in outcome manufacturing. Expert Systems with Application 22, 213-224.

Dargi, A., Anjomshoae, A., Galankashi, M.R., Memari, A., Tap, M.B.M., 2014. Supplier Selection: A fuzzy-ANP Approach. Procedia Computer Science 31(Supplement C), 691-700.

De Boer, L., Van Der Wegen, L., Telgen, J., 1998. Outranking methods in support of supplier selection. European Journal of Purchasing \& Supply Management 4, 109-118.

Dickson, G. W., 1966. Analysis of vendor selection systems and decisions. Journal of Purchasing and Supply Management 2, 5-17.

Ellram, L. M., Carr, A., 1994. Strategic purchasing: A history and review of the literature. International Journal of Purchasing and Materials Management 30, 10-18.

Eshtehardian, E., Ghodousi, P., Bejanpour, A., 2013. Using ANP and AHP for the supplier selection in the construction and civil engineering companies; Case study of Iranian company. KSCE Journal of Civil Engineering 17, 262-270.

Fletcher, J., 1994. The mean-variance efficiency of benchmark portfolios: UK evidence. Journal of Banking \& Finance 18, 673-685.

Gencer, C., Gürpinar, D., 2007. Analytic network process in supplier selection: A case study in an electronic firm. Applied Mathematical Modelling 31. 2475-2486.

Ghodsypour, S.H., O’Brien, C., 1998. A decision support system for supplier selection using an integrated analytic hierarchy process and linear programming. International Journal of Production Economics 56-57(Supplement C), 199-212.

Ghodsypour, S.H., O’Brien, C., 2001. The total cost of logistics in supplier selection, under conditions of multiple sourcing, multiple criteria and capacity constraint. International Journal of Production Economics 73, 15-27.

Hozo, S. P., Djulbegovic, B., Hozo, I., 2005. Estimating the mean and variance from the median, range, and the size of a sample. BMC Medical Research Methodology 5, 13. 
Huang, X., 2012. Mean-variance models for portfolio selection subject to experts' estimations. Expert Systems with Applications 39, 5887-5893.

Humphreys, P., Huang, G., Cadden, T., McIvor, R., 2007. Integrating design metrics within the early supplier selection process. Journal of Purchasing and Supply Management 13, 42-52.

Jharkharia, S., Shankar, R., 2007. Selection of logistics service provider: An analytic network process (ANP) approach. Omega 35, 274-289.

Jian, L., Fong-Yuen, D., Vinod, L., 2000. Using data envelopment analysis to compare suppliers for supplier selection and performance improvement. Supply Chain Management: An International Journal 5, 143-150.

Joro, T., Na, P., 2006. Portfolio performance evaluation in a mean-variance-skewness framework. European Journal of Operational Research 175, 446-461.

Kannan, V.R., Tan, K.C., 2002. Supplier selection and assessment: Their impact on business performance. Journal of Supply Chain Management 38, 11-21.

Katsikeas, C.S., Paparoidamis, N.G., Katsikea, E., 2004. Supply source selection criteria: The impact of supplier performance on distributor performance. Industrial Marketing Management 33, 755-764.

Lee, A.H.I., Kang, H.-Y., Hsu, C.-F., Hung, H.-C., 2009. A green supplier selection model for high-tech industry. Expert Systems with Applications 36, 7917-7927.

Li, X., Zhao, C., 2009. Selection of suppliers of vehicle components based on green supply chain. Proceeding of IEEE (Institute of Electrical and Electronics Engineers) International Conference on Industrial Engineering and Engineering Management 2009, Beijing, China. 1588-1591.

Luzzini, D., Caniato, F., Spina, G., 2014. Designing vendor evaluation systems: An empirical analysis. Journal of Purchasing and Supply Management 20,113-129.

Mafakheri, F., Breton, M., Ghoniem, A., 2011. Supplier selection-order allocation: A two-stage multiple criteria dynamic programming approache. The International Journal of Production Economics 132, 52-57.

Markowitz, H., 1952. Portfolio selection. Journal of Finance 7, 77-91.

Nelson O.N., Muhamad, J., Loo, C. H., Mat, S. A., 2005. Supplier selection and management strategies and manufacturing flexibility. Journal of Enterprise Information Management 18, 330 - 349.

Saaty, T. L., 1980. The Analytic Hierarchy Process. New York: McGraw-Hill.

Saaty, T. L., 1999. Fundamentals of the Analytic Network Process. Paper presented at the 5th International Symposium on the Analytic Hierarchy Process (ISAHP) 1999, Kobe, Japan. 1-14.

Verma, R., Pullman, M.E., 1998. An analysis of the supplier selection process. Omega 26, 739-750.

Weber, C.A., Current, J.R., Benton, W.C., 1991. Vendor selection criteria and methods. European Journal of Operational Research 50, $2-18$.

Weber, C.A., 1996. A data envelopment analysis approach to measuring vendor performance. Supply Chain Management: An International Journal 1, 28-39.

Weber, C.A., Desai, A., 1996. Determination of paths to vendor market efficiency using parallel coordinates representation: A negotiation tool for buyers. European Journal of Operational Research 90, 142-155.

Xiao, Z., Chen, W., Li, L., 2012. An integrated FCM and fuzzy soft set for supplier selection problem based on risk evaluation. Applied Mathematical Modelling 36, 1444-1454.

Yan, G., 2009. Research on green suppliers' evaluation based on AHP and genetic algorithm. Proceedings of IEEE (Institute of Electrical and Electronics Engineers) International Conference on Signal Processing Systems 2009, Singapore. 615-619. 